\title{
Contribuição ao estudo do mal de cadeiras na Ilha de Marajó *
}

\author{
por \\ Geth Jansen \\ (Com 5 estampas) \\ INTRODUÇÃO
}

Entre as diversas doenças de carater endêmico existentes no país, tambem o mal de cadeiras constituiu objeto da atenção do Serviço de Estudo das Grandes Endemias, não só pelo interesse científico como pela importância econômica de seu estudo.

Por isso fomos encarregados pelo Dr. Evandro Chagas de estudar essa doença, escolhendo como local de investigações preliminares a ilha de Marajó, onde o mal de cadeiras existe desde há muito, tendo sido, alem disso, aí estudado pelo $\mathrm{Dr}$. Adolpho Lutz, de modo que já contávamos com valiosas observações.

Nossos trabalhos foram feitos no Instituto de Patologia Experımental Evandro Chagas, do Jará, e foram facilitados pelo interesse e gentileza dos proprietários das fazendas que inspecionamos, aos quais agradecemos cordialmerte.

Considerando que a distribuição e o modo de vida dos homens e rebanhos são regidos pelas diversas condições e clima oferecidos pela ilha, passamos a fazer uma descrição suscinta desses fatores.

AS Diversas formações DA ILHA - A ilha de Marajó está situada entre as duas embocaduras do rio Amazonas, o estuário do rio Pará e o Amazonas propriamente dito.

* Recebido para publicação a 1 de agosto e dado à publicidade em novembro de 1941.

( ${ }^{\star}$ ) Trabalho do Serviço de Estudo das Grandes Endemias, Instituto Oswaldo Cruz. Superintendente interino: Prof. Carlos Chagas Filho. 
Sua forma é quase quadrangular, tendo de comprimento, no sentido leste-oeste, 143 milhas geográficas, ao longo da costa norte, e sua maior largura é de cerca de 90 milhas. Sua superfície abrange 42.000 quilômetros quadrados.

Como as demais ilhas localizadas no estuário do Amazonas, é a ilha de Marajó de formação aluvial.

Segundo Friedrich Katzer, "na costa noroeste, perto de Chaves e Afuá, e na secção sudeste, entre Curralinho e Soure, é formada por sedimentos, restos da terra marginal duma parte da embocadura onde outrora correu $o$ Amazonas. Com toda a probabilidade, nessa época, a corrente se escoava, talvez de Gurupá, ná direção nordeste através da atual ilha de Marajó, recebendo na região de Breves, do sudoeste, um caudaloso afluente que, ao que parece, se escoava do Xingú de hoje, pela baía de Caxiúnas do rio Anapú".

Explica ainda F. Katzer que os extensos charcos (mondongos) e pântanos existentes entre a baia de Caxiúna e os estreitos de Breves, entre estes, o Anajás e os pântanos do cabo Maguary, taziam o curso antıgo da corrente, que posteriormente se obstruiu por sedimentação, tornando-se terra firme; mas, que subsiste nesse antigo curso grande quantidade de água subterrânea, que aflue à superfície da terra nas depressões do terreno, dancio então a lormação dos mondongos e dos lagos sem tributários. Na época das chuvas a água subterrânea, elevando-se mais, impede a intiltraçao das águas pluviais no solo e as depressões secas enchem-se d'água, os pequenos charcos tornam-se lagos e os lagos aumentam muitas vezes a sua superfície. Nesta época, Marajó, em grande parte coberta pelas águas, tem um aspecto inteiramente diferente do que apresenta no verão, durante o qual o nivel das águas subterrâneas está muito mais baixo, permitindo a infiltração. Os pântanos vão secando até se tornarem em alguns casos vadeaveis e os lagos transtormam-se em pequenas poças. chegando às vezes a secar completámente.

A região pastoril da ilha de Marajó, que ocupa cerca de metade da ilha, é representada por campos que dão a essa região um aspecto inteiramente diferente daquele observado na outra metade, cujas características são semelhantes às da mata amazônica em geral.

Os campos de Marajó, conforme seu aspecto topográfico, são classificados em quatro tipos. Us campos altos e seus tesos, as baixas rasas, as baixas fundas e os mondongos. 
Nas zonas por nós observadas (municípios de Muaná, Cachoeira e Soure) predominam os três primeiros tipos, bem distintos entre si por seu facies e vegetação.

Nos campos altos ou campos cobertos, sempre arenosos e de vegetação subxerófila, podem ser vistas a carobeira (Tecoma caraiba), o caimbé (Curatella americana), o murici do campo (Byrsonima crassifolia), o tucuman (Astrocaryum vulgare), etc. São esses campos, bem como os tesos que neles ocorrem, pobres de plantas forrageiras. A graminea que ar predomina, é a barba de bode (Eragrostris reptans), de contextura lenhosa e rica em sílica, que a torna imprópria para a alimentação do gado.

Constituidas as baixas rasas por depressões de grande superfície $e$ declive mínimo, submergem inteiramente por ocasião das chuvas (inverno), não impedindo, porem, que os animais ai permaneçam o dia todo em busca de alimentaçáo, constituida por ótimas plantas forrageiras, predominarıdo as canaranas (Panicum spectabile e outras espécies do mesmo gênero) e andréquicé (Leersia hexandra), que emergem em abundância à superfície das águas. É este o tipo de campo o melhor para criação, porque, sem o exagero dos enormes alagados que no inverno existem nas baixas fundas, não sofrem no verão os efeitos da seca violenta, vista como o maior grau de umidade do solo torna possivel uma vegetação abundante no periodo estival.

Nesses campos das baixas rasas, ou campos lavrados, existem as chamadas "ilhas", que são grupamentos arbóreos, perfeitamente diferenciados do campo que os circunda, com um tipo de vegetação de sub-bosque.

A baixa funda é formada por depressões mais sensiveis, diferindo do tipo anterior, pela grande quantidade de humo aí existente, o que condiciona maior exuberância de vegetação.

Durante o verão, e em virtude do escoamento muito lento das águas, as baixas não secam inteiramente, constituindo brejos, onde numerosos animais, quando alí vão ter em busca de águá, murrem atolados.

Ambos os tipos de baixas citados apresentam, na sua configuração, ondulações suaves de terreno e possuem elevações às vezes bem extensas (íesos), que não são atingidos pelas cheias.

É nos tesos que o gado se reune à tarde, para dormir depois de haver passado c dia dentro d'água à procura da alimentação.

Os mondongos, ao contrário, quase não possuem tesos. Permanecem submersos a maior parte do ano. O tipo de vegetação aí predominante é a higrotila. 
FORRAGEIRAS - As plantas forrageiras de Marajó sāo constituidas em grande parte por gramineas, algumas ciperáceas e leguminosas.

Nos tesos dos campos altos, as principais săo: capim de toice (Paspalum sp.). pé de galinha (Eleusine indica), capim de botão (Cyperus luzulae), etc.

Nos campos das baixas rasas: capım roxo (Paspalum parvifolium), canarana fina (Panicum appressum ou $P$. laxum), canarana miuda (Panicum amplexicaule), canarana roxa (Panicum zizanioides), andré-quicê (Leersia hexandra), canarana rasteira (Paspalum repens), canarana grande (Panicum spectabile), etc.

ESTAÇÕEs - Como em toda a Amazônia, notam-se em Marajó apenas duas estações no ano: inverno ou época das chuvas e verão ou época da seca.

O inverno começa em janeiro-fevereiro e prolonga-se até junho-julho, época em que as chuvas vão cessando, para dar lugar ao veran. As águas, que no inverno inundavam os campos, deixando a descoberto apenas os "tesos", vão baixando gradualmente, até que o terreno seca quase totalmente. Nessa época de seca, que atinge a maior intensidade de outubro a dezembro, apenas nas grandes depressões permanece o terreno umido, corn algumas coleções de água, constituindo os chamados "atoleiros".

INSFros tikmárófagos - A maior ou menor densidade de insetos hematófagos está relacionada com a época das chuvas. Aparecem em JaneiroFevereiro, aumentando gradualmente de número até atingirem a máxima intensidade de frequência em Março-Abril. Depois decrescem, tornandose mais raros, com as grandes águas. Tomam maior incremento no fim do periodo das águas, diminuindo com a entrada do verão, desaparecendo praticamente na estação seca. São os animais grandemente perseguidos pelos insetos hematólagos, principalmente nos campos cobertos $e$ ilhas de mato.

MORCEGOS HEMATÓFAgos - Os morcegos hematófagos ocorrem em todas as épocas do ano, sem que, entretanto, o número de animais sugados seja muito grande.

SANGUE-SUGAS - As sangue-sugas atacam de preferência os bovinos, por isso que esses animais permanecem pastando nas baixas, enquanto que os equinos, por sua maneira de preensão dos alimentos, preferem as pástagens rasteiras próprias dos tesos.

INDÚSTRIA PASTORIL - A criação de gado na ilhá alncia e praticada de modo extensivo. O gado, quer bovino quer equino, é criado solto nos 
campos e reunido anualmente para contagem, marcação e castração. Para esse fim escolhem os fazendeiros os meses de outubro a dezembro, época err que o terreno, completamente seco, favorece o trabalho.

Observamos que, terminada essa fase de trabalho intenso, os cavaios de serviço apresentam um aspecto desolador motivado pelo excesso de atividade, pois o gado bovino, apenas semi-domesticado, exige um trabalho rude e intenso para mantê-lo reunido em suas malhadas ou lotes. O vaqueiro $\mathrm{faz}$ às vezes três e quatro jornadas montando o mesmo animal que trabalha o dia todo sem descansu.

Ao trabalho árduo se alia a deficiência de alimentaçäo originárı da pobreza de pastagens, pois é justamente na época das vaquejadas que a seca se faz sentir com maior intensidade.

HISTórico - Segundo J. B. de Lacerda, em seu trabalho publicado em 1885 - Peste de cadeiras ou Epizootia de Marajó - o mal de cadeiras surgiu em Marajó, em época determinada aproximadamente entre 1827 e 1830. Nesta época o número de equinos na ilha era tal (1.000.000), que fizeram grandes matanças desses animais para o comércio de couros, os quasi eram vendidos ao preço unitário de 500 rểs.

Atribuiram os criadores desse tempo a origem da doença, que apareceu em seguida, ao envenenamento do ar pelas carcassas em decomposição.

Desde essa época até nossos dias, grassa em Marajó o Mal de Cadeiras; entretanto, informações, colhidas por nós, de diversos criadores faziam referências ao desaparecimento, nestes últimos cinco anos, dessa zoonose.

Em 1907, estudando o mal de cadeiras, esteve em Marajó o professor Adolpho Lutz, que concluiu ser o mal de cadeiras transmitido por Tabanídeos e acho:ı que a capivara (Hydrochoerus capybara) era o depositário do Tripanosoma causador dessa doença.

Dando início aos nossos trabalhos, fizemos um inquérito sumario entre alguns fazendeiros da região que iria constituir local de nossos estudos. Todos foram acordes em afirmar não existir mais o mal de cadeiras. Atribuiam a grande mortalidade dos cavalos de Marajó, que então se verificava, a uma doença que denominavam de "barriga inchada" e "mormo seco". Verificamos que os cavalos doentes de "barriga inchada" e "mormo seco", eram animais atacados pelo mal de cadeiras. A barriga inchada, que dá o nome à doença, é o edema do ventre. sintoma quase constante nos numerosos casos de mal de cadeiras que vimos. 
MÉTODo DE TRABALHo - Nas inspeções obedecemos ao seguinte plano de trabalho:

$\left.1 .^{\circ}\right)$ Fazíamos o exame clínico dos animais, que consistia na verificação dos sintomas clássicos, sendo a anemia avaliada pelo método de Talqvist.

$\left.2 .^{\circ}\right)$ Pesquisávamos o 'l'rypanosoma pelo exame de sangue a fresco e por inuculação em camondongos ou ratos brancos em todos os casos negativos pelo exame direto.

Tanto o exame clínico como a pesquisa de parasito eram feitos sistematicamente em todos os animais.

Notamos desde logo vários animais sem sintomas clínicos, com exames de sangue a fresco negativos, entretanto a inoculação em ratos brancos revelou Trypanosomas; estes eram, principalmente, cavalos do uso particular de tazendeiros ou administradores, sob um regime de trabalho menos intenso e melhor alimentados que os demats.

Como se vê no quadro $n$. 1, o exame por inoculação revelou maior número de casos positivos que o exame direto.

Fizemos tambem captura sistemática de hematótagos, com o fim de veriticar a possivel relação de sua maior ou menor incidência com o apare. cimento da epizootia.

Em todas as fazendas que inspecionamos obtivemus dos tazendeiros dados sobre a mortalidade de equinos, os quars apresentaremos mais adiante e que nos dão uma idéia da importância econômica da doença na região.

LOCALIDADES INSPECIONADAS - As nossas inspeções foram feitas nas seguintes fazendas :

Fazendas de propriedade do Dr. Agostinho Monteiro - Município de Cachoeira, região do Arary: 2 inspeçoes.

Fazenda da firma F. J. Cardoso - Município de Lachoeira, regiao do Alto Camará: 4 inspeçoes.

Fazendas de propriedade do Sr. Claudio Monard - Municipio de Soure: 1 inspeção.

Fazendas de propriedade do Dr. José Ferreira Teixeira - Município de Muaná: 1 inspeção.

Fazendas de propriedade do Sr. Fernando Teixeira e Irmãos - Município de Muaná: 1 inspeção.

Fizemos, pois, um total de 9 inspeções nos diterentes meses do ano. 
Todas essas fazendas estavam situadas na região dos campos, apresentando aspectos semelhantes.

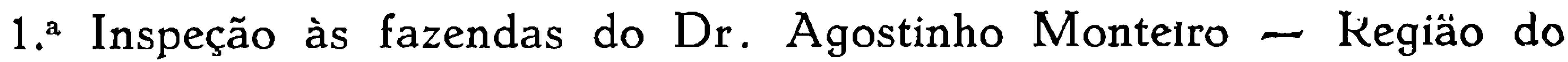
Arary. Feita entre 27/10/38 e 5/11/38.

Total de equinos .................... 139

Equinos examinados .................. 139

Positivos por exame a fresco do sangue ....... 1

Positivos por inoculação de camondongos ...... 3

Percentagem de infecção $\ldots \ldots \ldots \ldots \ldots . \quad 2,9 \%$

Dados fornecidos pelo gerente da fazenda :

População de equinos em $1937 \ldots \ldots \ldots \ldots \ldots . \quad 221$

Equinos mortos em $1937 \ldots \ldots \ldots \ldots \ldots \ldots \ldots 61$

Mortalidade em $1937 \ldots \ldots \ldots \ldots \ldots \ldots \ldots$ 27,6\%

População de equinos em $1938 \ldots \ldots \ldots \ldots \ldots . \quad 140$

Equinos mortos em $1938 \ldots \ldots \ldots \ldots \ldots \ldots$. 79

Mortalidade em $1938 \ldots \ldots \ldots \ldots \ldots \ldots \ldots$

2.: Inspeção às fazendas do Dr. Agostinho Monteiro - 15 a 23 de abril de 1939 :

Total de equinos .................... 139

Equinos examinados .................. 130

Positivos por exame a fresco do sangue ...... 21

Positivos por inoculação em camondongos ...... 13

Total de animais infetados .............. 34

Percentagem de infeção nos animais exami-

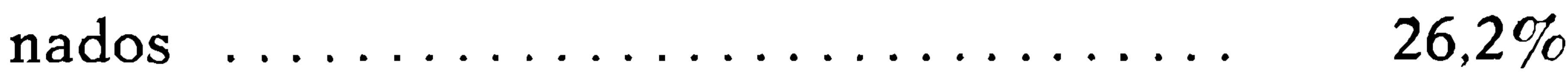

1.a Inspeção às fazendas da firma F. J. Cardoso ( $\left.{ }^{\star}\right)$ - Região do Alto Camará - 11/7/1939 a 22/7/1939.

Total de equinos ................... 132

Equinos examinados ................. 108

Positivos por exame a fresco do sangue ....... 48

Positivos por inoculação em camondongos ...... 20

Total de animais infetados $\ldots \ldots \ldots \ldots \ldots .68$

Percentagem de infecção nos animais examinados $\ldots \ldots \ldots \ldots \ldots \ldots \ldots \ldots \ldots \ldots \ldots$

(*) As propriedades da firma F. J. Cardoso compõem-se de um grupo de fazendas reunidas lindeiras entre si. 
Distribuição dos animais por fazendas :

Santa Maria - 26 cavalos 11 positivos por exame a fresco de sangue

\begin{tabular}{|c|c|c|c|}
\hline Maria Pana & -26 & " & 15 \\
\hline Pauxís & -9 & $"$ & 2 \\
\hline Guaribas & -3 & $"$ & 1 \\
\hline Taperebás & -15 & $"$ & 8 \\
\hline São Paulo & -12 & $"$ & 7 \\
\hline Livramento & -8 & $"$ & 4 \\
\hline Maria José & -9 & •" & $u$ \\
\hline
\end{tabular}
do Fogo"

Nesta primeira excursão não foram examinados os animais da "Ilha

Dados tornecidos pelo administrador das fazendas: população de equinos em abril de 1939: 252 animais. Morreram de abril a julho de 1939, 142 animais, incluindo os da Ilha do Fogo.

2.2. Inspeção às fazendas da firma F. J. Cardoso - 27/8/939 a 15/9/939.

Verificamos que no espaço de tempo decorrido entre a prımeira e a segunda excursão (pouco mais de um mês), morreram 38 animais, dos quais 34 notificados anteriormente como doentes de Mal de Cadeiras e 4 adquiriram posteriormente a doença, segundo informações que nos foram dadas pelo gerente das fazencias.

Esses animais estavam assim distribuidos:

\begin{tabular}{|c|c|c|}
\hline Santa Maria & & t1mats \\
\hline Maria Pana & $y$ & " \\
\hline Pauxís & 2 & $"$ \\
\hline Taperebás & 8 & 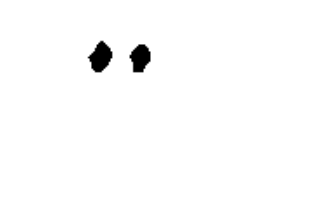 \\
\hline São Paulo & 7 & $"$ \\
\hline Livramento & 3 & $"$ \\
\hline
\end{tabular}

Equinos examinados 167 i.é. todos os animais existentes, dos quais 70 já examinados na excursão passada, 73 recem-chegados da fazenda de Camburupy - Município de Soure - e 24 pertencentes à llha do Fogo onde não estivemos na excursáo anterior.

Verificamos 13 novos casos de infecção, dos quais dois diagnosticados pelo exame a fresco do sangue e os demais por inoculação em camondongos. Esses cavalos pertencem: 6 à fazenda Santa Maria; 5 à fa zenda Maria Pana; 2 à fazenda Pauxís. 
Dos animais pertencentes a fazenda da Ilha do Fogo, veriticamos 14 casos positivos, sendo 10 por inoculação em camondongos brancos e 4 por exame a fresco do sangue.

Não veriticamos nenhum caso positıvo nos animais provenientes da Fazenda Camburupy. Esta propriedade, se bem que pertencente à firma F. J. Cardoso, não faz parte do grupo de fazendas localizadas nu Município de Cachoeira e sim ao Município de Soure, ficando o citado estabelecimento muito distante dos demais.

Para comparar os resultados dessa segunda inspeçâo com us da primeira, eliminamos das percentagens os cavalos recem importados ou não examinados na excursão anterior.

Percentagem de infecção

$67,1 \%$

Incluindo os 24 animais da ilha do Fogo teriamos 64,9\% de infecções e, levando em conta tambem os de Camburupy, a percentagem cairia a $36,5 \%$, resultado este que servirá de termo de comparação nas inspeçōes posteriores.

Mortalidade $35,2 \%$

3. ${ }^{a}$ Inspeção às fazendas da firma F. J . Cardoso, feita entre 25/9/39 e $11 / 10 / 39$.

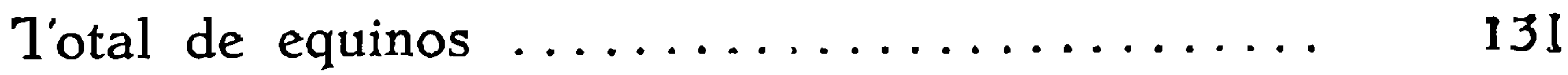

Equinos re-examinados $\ldots \ldots \ldots \ldots \ldots \ldots \ldots \quad 120$

Novas infecçoes

Positivos por exame de sangue a tresco ..... 3

Positivos por inoculação em camondongo .....

No espaço de tempo decorrido entre a segunda excursáo e a terceira, morreram 36 equinos, todos relacionados nas excursões anteriores como doentes de Mal de Cadeiray.

Percentagem de infecçōes $\ldots \ldots \ldots \ldots \ldots \ldots . \quad 29,2 \%$

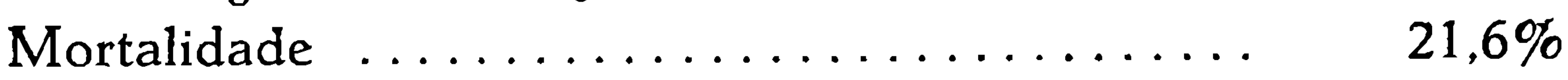

4. ${ }^{a}$ Inspeção às fazendas da firma F. J. Cardoso entre 26/10/39 e $10 / 11 / 39$.

Total de equinos $\ldots \ldots \ldots \ldots \ldots \ldots \ldots \ldots$ yi

Equinos examinados $\ldots \ldots \ldots \ldots \ldots \ldots \ldots . . \ldots 1$

Novas infeçōes

Positivos por exame a fresco do sangue ........

Positivo por inoculações em camondongo ....... 1 
Os equinos doentes pertencem 3 à fazenda Taperabás; 2 à Ilha do Fogo; 1 à fazenda Santa Maria.

No espaço de tempo decorrido entre a excursão anterior e a presente, verificamos terem morrido 29 animais, todos notificados nas excursões passadas como doentes de Mal de cadeiras. É a seguinte a distribuição desses animais por fazendas :

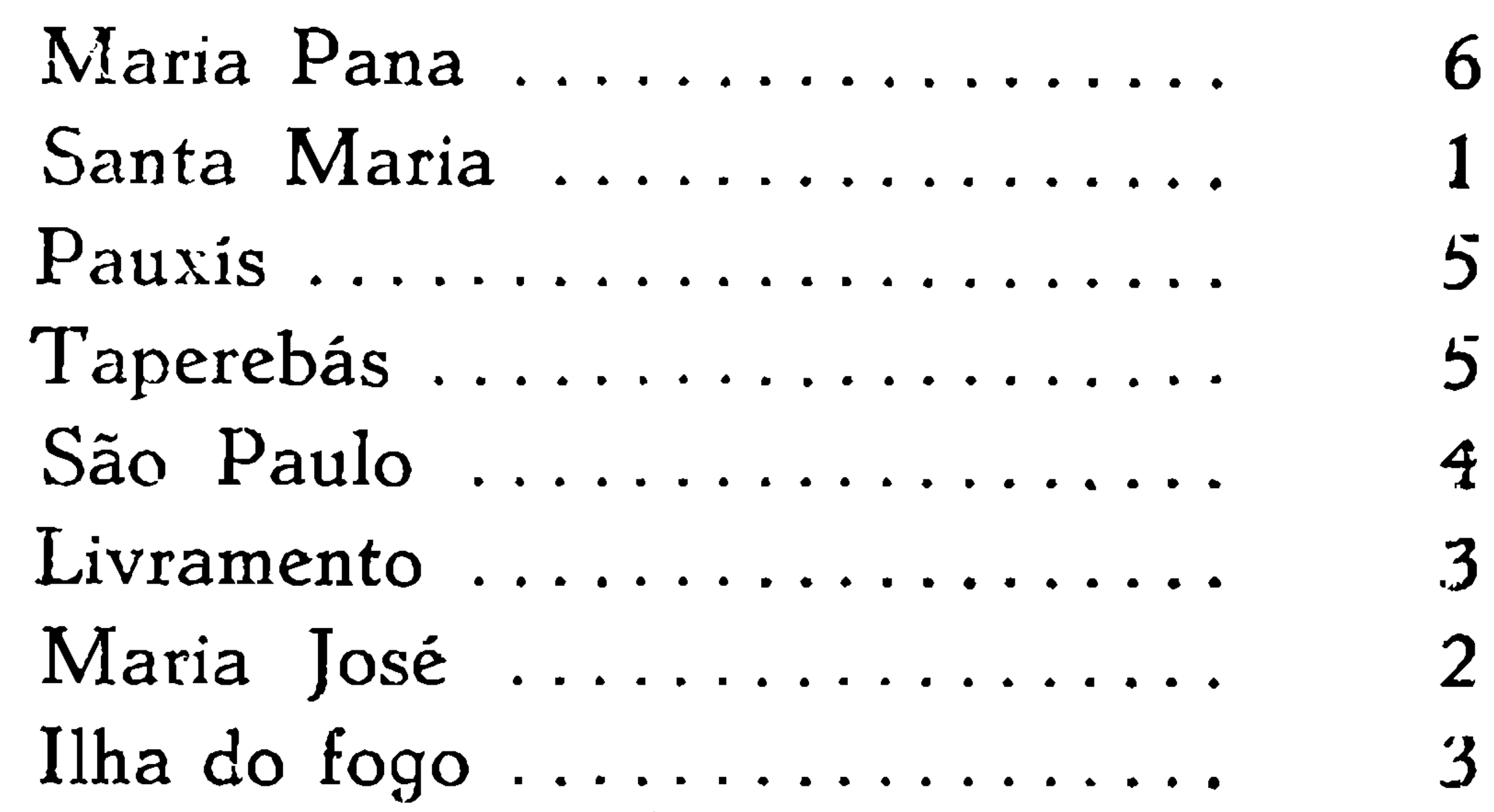

Percentagem de infecções $\ldots \ldots \ldots \ldots \ldots \ldots$ 13,2\%

Mortalidade .................. 24,2\%

Excursão às fazendas do $\mathrm{Sr}$. Claudio Monard, Município de Soure - Região do Alto Camará. Feita entre 26/10/39 e 10/11/39.

Total de equinos ................... 197

Equinos examinados ................. 197

Positivos por exame a fresco do sangue ...... 0

Positivos por inoculação em camondongo ...... 1

Percentagem de infeção $\ldots \ldots \ldots \ldots \ldots \ldots \ldots . . \ldots, 5 \%$

Excursão feita às fazendas de propriedade de Fernando Teixeira e Irmãos. Feita entre 15 a 22 de novembro de 1939.

Total de equinos .................... 119

Equinos examinados .................. 119

Positivos por exame a fresco ............. 0

Positivos por inoculação em camondongo ...... 1

Percentagem de infecção $\ldots \ldots \ldots \ldots \ldots \ldots . \quad 0,8 \%$

Fazenda São Manoel :

Dados fornecidos pelo proprietário: Cavalos existentes em março de 1939, 46; atualmente (nov.), 3. Morreram 43. Os restantes nada acusaram nos exames procedidos.

Mortalidade 
Excursão feita à fazenda de propriedade do Dr. José Teixeira. Feita de 22 de novembro a 1 de dezembro de 1939 .

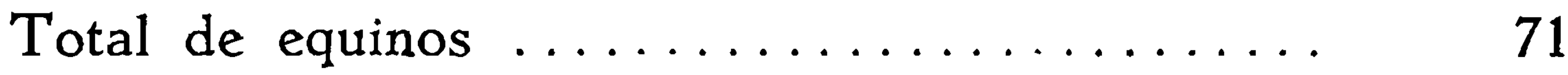

Equinos examinados $\ldots \ldots \ldots \ldots \ldots \ldots \ldots \ldots, 71$

Positivos por exame a fresco do sangue ...... 0

Positivos por inoculação $\ldots . \ldots \ldots \ldots \ldots \ldots . . \ldots$

Percentagem de animais infectados ......... $0 \%$

Resultado geral

Exames feitos em equinos na ilha de Marajó durante o ano de 1939:

Total de exames feitos ............... 1.142

Total de equinos examinados ............. 731

Positivos por exame a fresco do sangue ...... 84

Positivos por inoculação em camondongo .... 67

Total de infecções .................. 151

Percentagem de infecções $\ldots \ldots \ldots \ldots \ldots \ldots \quad 20,7 \%$

Como repetíssemos as inspeções às fazendas do Dr. Agostinho Monteiro e da firma F. J. Cardoso, pudemos verificar animais sem sintomas, com Trypanosomas no sangue durante seis e quatro meses respectivamente, muitos dos quais, segundo o questionário mensal respondido pelos fazendeiros, viviam em estado de saude aparente com mais de um ano de infecção, constituindo, assim, depositários do Trypanosoma, capazes de explicar a existência do mal de cadeiras enzooticamente na ilha de Marajó.

Como já referimos, esses animais eram os mais poupados e, uma vez submetidos a regime de trabalho intenso, apresentavam dentro de pouco tempo todo o quadro clínico característico da doença.

Nào nos toi possivel verificar a asserçâo de ser a capivara (Hydro. choerus capybara) depositária do agente etiológico do mal de cadeiras, porque, devido à valorização do couro desse roedor e mesmu da carne, muito apreciada em algumas cidades do interior do Pará, este animal, por muito 'perseguido, é hoje quase inexistente na ilha de Marajo.

Durante um ano de trabalho conseguimos examinar apenas dols exemplares com resultado negativo. Esse exterminio, entretanto, não 1mpediu que o mal de cadeiras continuasse na ilha como enzootia. 
QUADRO N. ${ }^{\circ} 1$

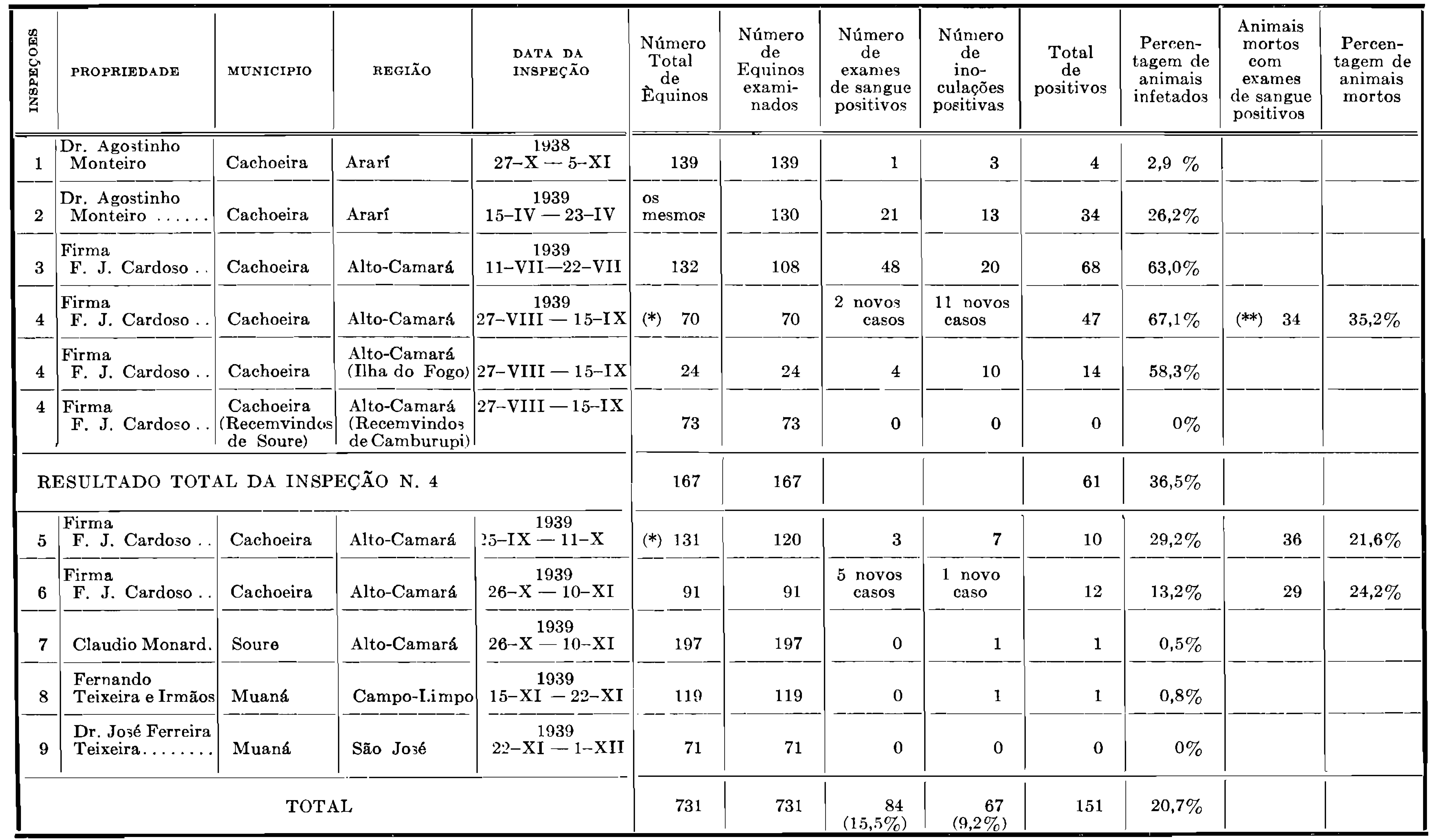

(*) Já examinados anteriormente.

(**) Além desses morreram mais 4 com mal de cadeiras, todos com exames negativos, na excursão anterior. 
Como se vê no quadro n. I, que resume os resultados das inspeçoes. a percentagem de animais infectados cresce de abril em diante, atingindo o maxımo em agosto e setembro, diminuindo nos meses seguintes, sobretudo pela grande mortalidade de animais doentes; de outubro em diante, a percentagem cal, atingindo o mínimo em dezembro.

A infecção parece estabelecer-se, pois, em seguida ao início das chuvas. época que marca o aparecimento dos insetos. Esta relação vem corroborar a opinião daqueles que como os profs. Lutz e Neiva incriminam os insetos hematótagos (Tabanideos) como responsaveis pela transmissão da doença.

\section{EXPERIENCIAS EM LABORATORIO}

Em nossas inspeções tivemos sempre a preocupação de colher ma. terial entomológico, especialmente os hematófagos, afim de conhecer a frequência desses insetos na região citada. A determinação desse macerral entregue a especialistas, ainda não chegou a nossas mãos, por isso não jun tamos a respectiva lista.

Os insetos acima referidos foram capturados em equinos. Grande número toi tambem colhido com armadilhas Shannon, que armamos nas ilhas de mato, próximas ao nosso estacionamento.

Procurando verificar a sobrevivência dos trypanosomas no tubo digestivo dos tabaníảeos e Stomoxys, utilizamos cerca de 30 exemplares desses dípteros, que foram postos a sugar em animais infectados. Estes insetos eram dissecados, de meia em meia hora, nas primeiras 24 horas apos o repasto, e seu conteudo digestivo microscopado, e mais tarde, entao, pas samos a examinar 48 horas depois da sucçao.

Os resultados desses exames demonstraram que os trypanosomas se conservam com vida e movimentos ativos até 7-8 horas depois de ingeridos. O material colhido nos exames feitos com 8 horas ou menos revelou-se capaz de infectar rátos brancos. Entretanto, depois de transcorrido esse periodo, mostraram-se os trypanosomas com movimentos diminuidos ou em tormas arredondadas degenenadas ao exame pelos processos derivados do método de Romanowsky. As inoculações feitas com este material deram resultados neyativos.

A dificuldade de manter um grande número de murcegos hematotagos em laboratório, pela precariedade dos meios de transporte que ocasionaram a morte da quase totalidade dos quirópteros deste grupo, enviados ae Marajó para Belem, e a pouca possibilidade de capturá-los na mesma cidade não nos permitiram executar uma série de experiências metódicas sobre o papel representado por estes animais na transmissão da zoonose em Marajó. 
Um único animal, pertencente à espécie Desmodus rotundus, foi utilizado e deste modo não pudemos apresentar resultados conclusivos. Fizemos previamente a pesquisa de Trypanosomas pelo exame a fresco e por inoculaçäo em camondongos, no sangue da espécie referida, atim de nos certificarmos da pureza do material com que trabalhavamos.

Verificada a negatividade dos exames, pusemos o morcego para ali. mentar-se $6 \cdot m$ cão infectado experimentalmente. Os exames efetuados de três em três dias revelaram a presença de Trypanosomas no sangue periférico do morcego ao cabo de 37 dias.

O cão infectado foi substituido desde o $41^{\circ}$ dia por um animal são da mesma espêcie.

'I'omamos as precauçöes devidas para impedir a presença de insetos no interior do box telado em que se processou a experiência, quer ao iniciá-la, quer no momento da substituição do cão. Com esse propósito utilizamos o Flit em aspersão rigorosa no interior do box.

O cão normal foi sugado, regularmente pelo morcego durante 80 dias, ao cabo dos quais morreu. O sangue desse cão foi examinado a fresco, diariamente, sempre com resultado negativo e com intervalos mais ou menos regulares, foi inoculado em camondongos e ratos brancos, tambem com resultado negativo.

Quanto ao morcego, examinado de três em três dias, sempre revelou a presença de trypanosomas no sangue, durante todo o tempo dessa experiência .

Simultaneamente aos exames de sangue, toi teita a pesquisa de flagelados na saliva, sempre negativa. Esta saliva foi inoculada repetidamente, e com intervalos de tempo mais ou menos regulares, em camondongos e ratos brancos, com resultado igualmente negativo. Para tornar mais abundante a secreção salivar, antes de colhermos o material, fizemos injeções subcutaneas de $0,30 \mathrm{cc}$. de nitrato de pilocarpina. Por esse processo, evitamos possiveis lesões da mucosa bucal consequentes à extração mecânica da saliva .

\section{Resumo e conclusöes}

Como resultado de inspeções feitas à ilha de Marajô o autor assinala:

$\left.1 .^{\circ}\right)$ O mal de cadeiras continua existindo na ilha de Marajó sob a forma enzoótica, ao contrário do que pensavam os criadores, julgando-o extinto. As doenças designadas por estes como "barriga inchada" e "mormo secu", responsaveis pela grande mortalidade dos equinos, foram identiticadas pelo autor como mal de cadeiras. 
$\left.2 .^{\circ}\right) \quad \mathrm{O}$ autor considera indispensavel para a pesquisa do irypanosoma o processo de inoculação em animais de laboratório, tendo utilizado para esse fim camondongos e ratos brancos.

3.') Os surtos epizoóticos anuais coincidem com a època das chuvas, ocasiäo em que surgem os insetos hematófagos, o que faz pensar no papel desses últimos como transmissores.

4. ) Os cavalos podem atravessar o ano com trypanosomas 110 sangue e em estado de saude aparente, constituindo assim depositários do mal de cadeiras.

5. ) O extermínio da capivara, em consequēncia do seu aproveitamento econômico não modificou o carater endêmico da doença na ilha de Marajó.

6.") O autor observou que os trypanosomas ilo tubo digestivo de Stomoxys e Tabanideos, ao cabo de 8 horas, apresentavam com movimentos diminuidos e em formas arrendondadas, não conseguindo inoculações positivas com esse material.

7.") A saliva de um morcego do gênero Desmodus, que se infectou no laboratório, alimentando-se em animal doente, colhida de modo a evitar lesões da mucosa e consequente contaminação pelos trypanosomas do sanguz circulante, mostrou-se incapaz de infectar, por inoculaçäo, animais sensiveis. Este mesmo morcego não transmitiu a doença a um cão, o qual sugou durante 80 dias.

Recentemente (1941) empregando um exemplar do gèneru Desmodus, tamlerm infectado experimentalmente por alimentação em animal de laboratório, conseguimos transmitir o Trypanosoma equinum a uma cobaia normal.

Este assunto será ventilado posteriormente.

\section{BIBLIOGRAFIA}

LACERDA, J. B. DE

1885. Peste de cadeiras ou epizootia de Marajó. Suas analogias com o beriberi. Lombaerts \& Cia., Rio de Janeiro.

Derby. Prof. O.

1897-8. A ilha de Marajó. Bol. Mus. Paraense. 2 (2):163.

Chermon de Miranda, V.

1907. Campos de Marajó e sua flora. Bol. Mus. Paraense. 5 (1): 96. 
Lutz, A.

1907. Estudos e ohservaçães sobre o quebra bunda ou peste de cadeiras. Diärio Oficial, Ano XIII, n. 4.780:355. Belém, Pará.

Neiva A. E Penna, B.

1916. Viagem cientifica pelo norte da Baía, sudoeste de Pernambuco, sul do Piali e norte a sul de Goiaz. Mem. Inst. Osw. Cruz, 8 (3): 152.

Katzer, F.

1933. A estrutura geológica da região do baixo Amazonas. Bol. Mus. Paraense E. Göeldi de Hist. Nat. E Etrog. 9:41.

\section{ESTAMPA 1}

Figs. 1 e 2 - Marajo - Aspectos dos "tesos" no verão. 
N.EM. INST. OSWALDO CRJZ

36 (3), SETEMB ?0, $1 \llbracket 4$ !

EST. 1
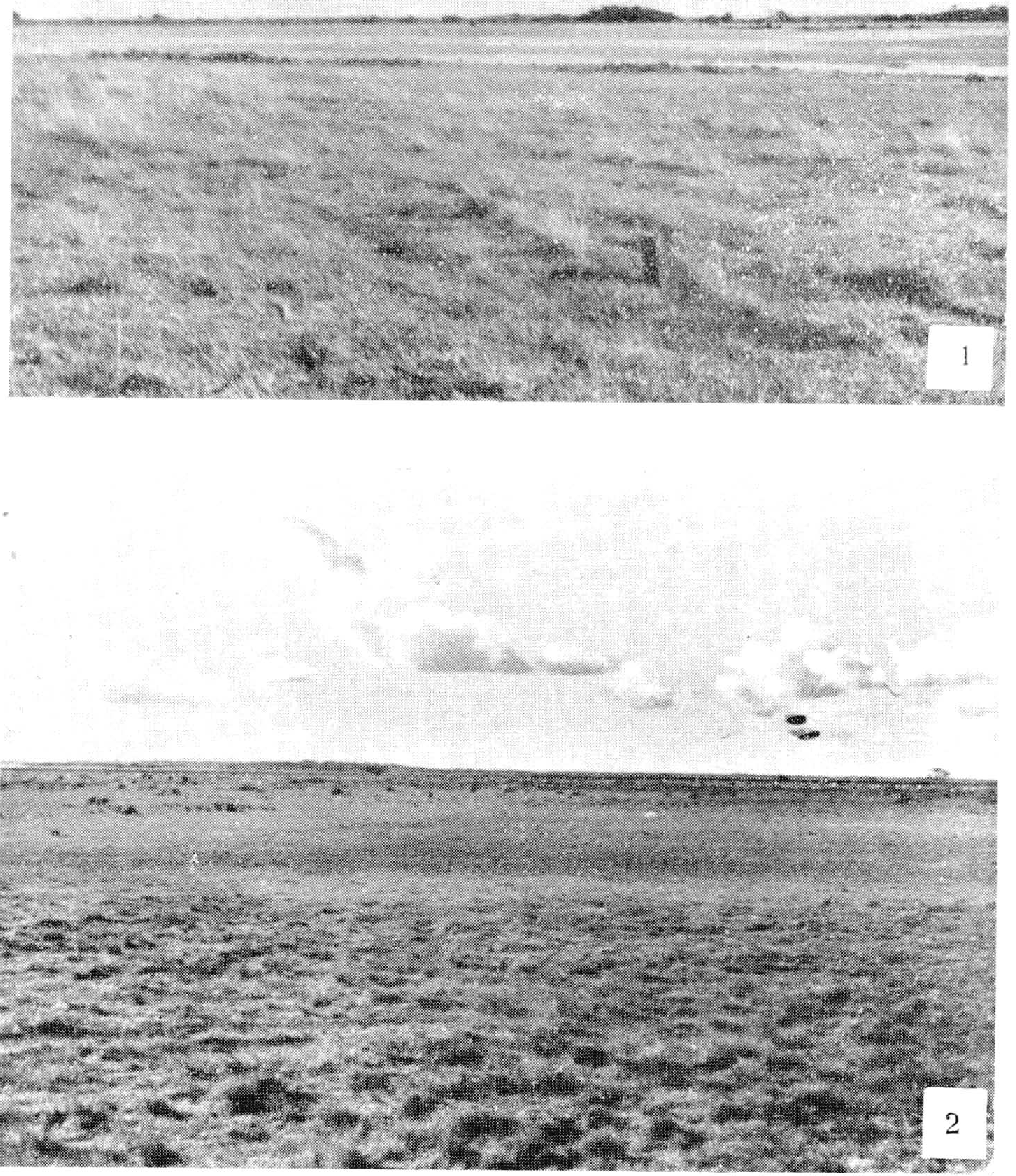

Jansen: Mal de cadeiras em Marajó 
ESTAMPA 2

Fig. 1 - Marajó - Aspectos das "baixas rasas" no invernu.

Fig. 2 - Marajó - Paisagem de inverno. 

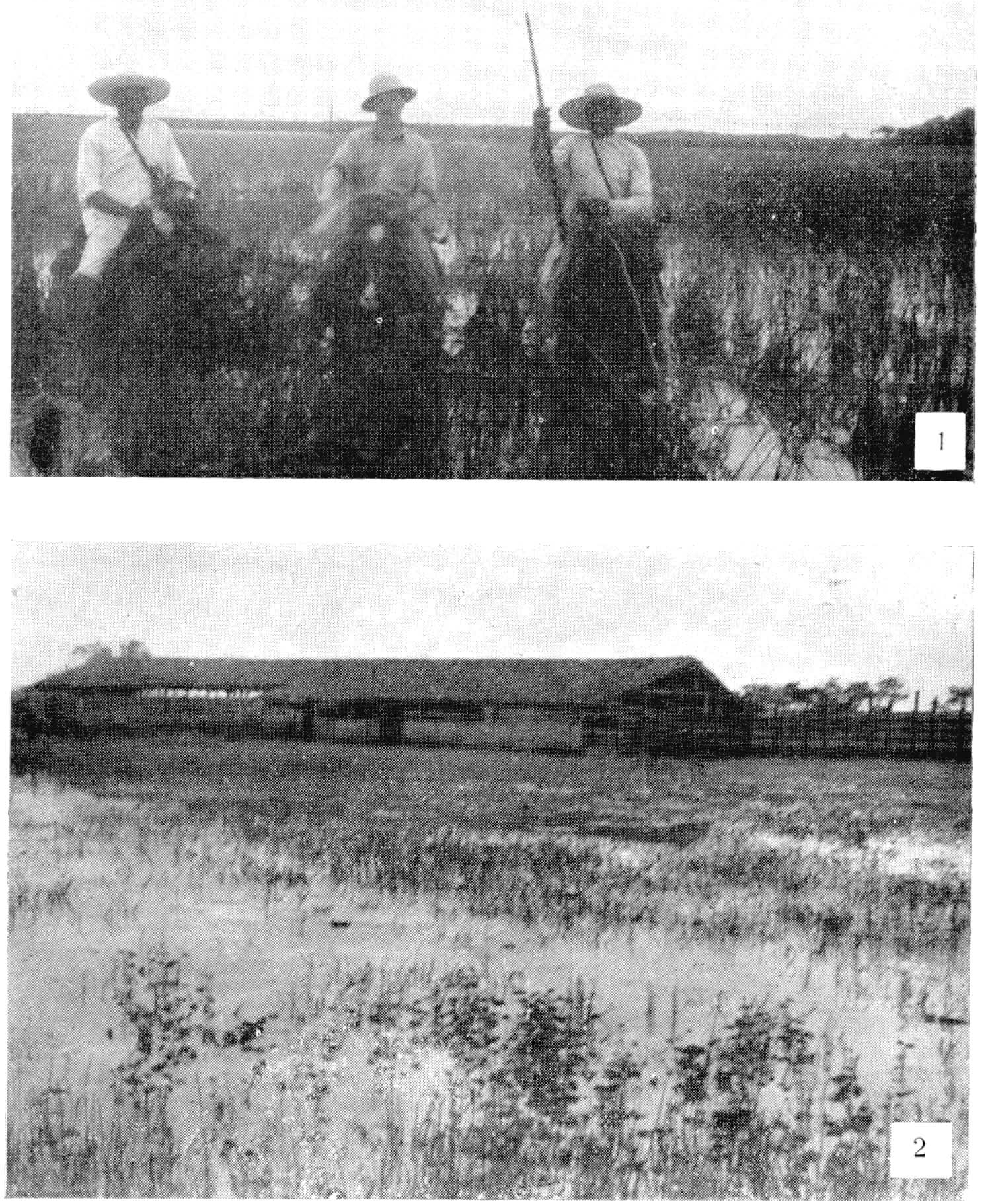

Jansen: Mal de cadeiras em Marajó 


\section{ESTAMPA 3}

Fig. 1 - Cavalo com mal de cadeiras. Edema do ventre e placas cutâneas com pelos eriçados.

Fig. 2 - Cavalo com mal de cadeiras. Fase adiantada da doença, na qual só a muito custo consegue o animal levantar-se. 

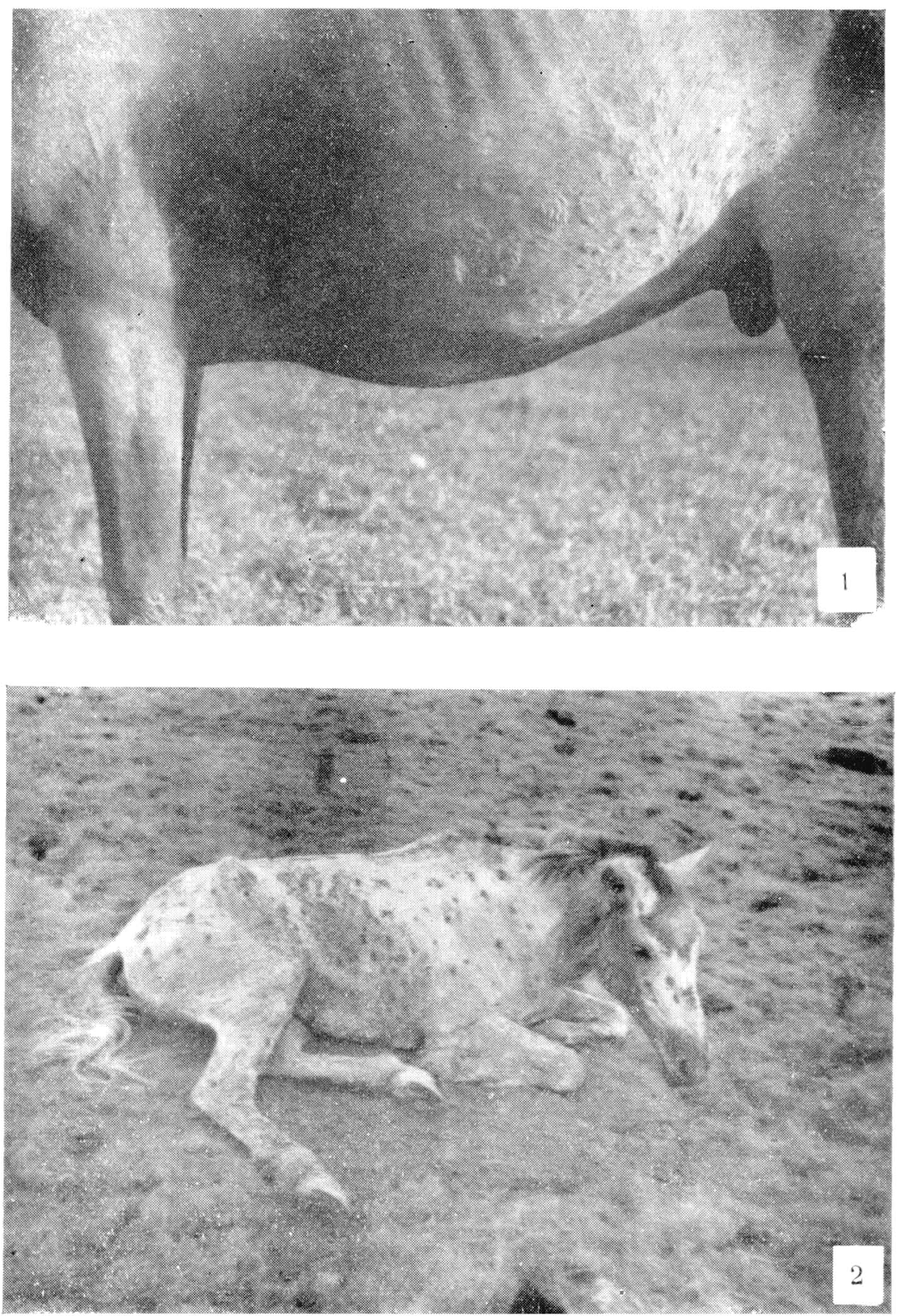

Jansen: Mal de cadeiras em Marajó 


\section{ESTAMPA 4}

Fig. 1 - Cavalo com mal de cadeiras: Note-se a abdução dos membros posteriores e o cruzamento dos anteriores, característico da incoordenação dos movimentos quando o animal caminha.

Fig. 2 - Cavalo com mal de cadeiras. Notem-se a posição baixa da cabeça e os membros estacados, procurando manter o equilibrio na posição de pé. 
MEM. INST. OSWALDO CRUZ

EST. 4

36 (3), SETEMBBRo, 1941
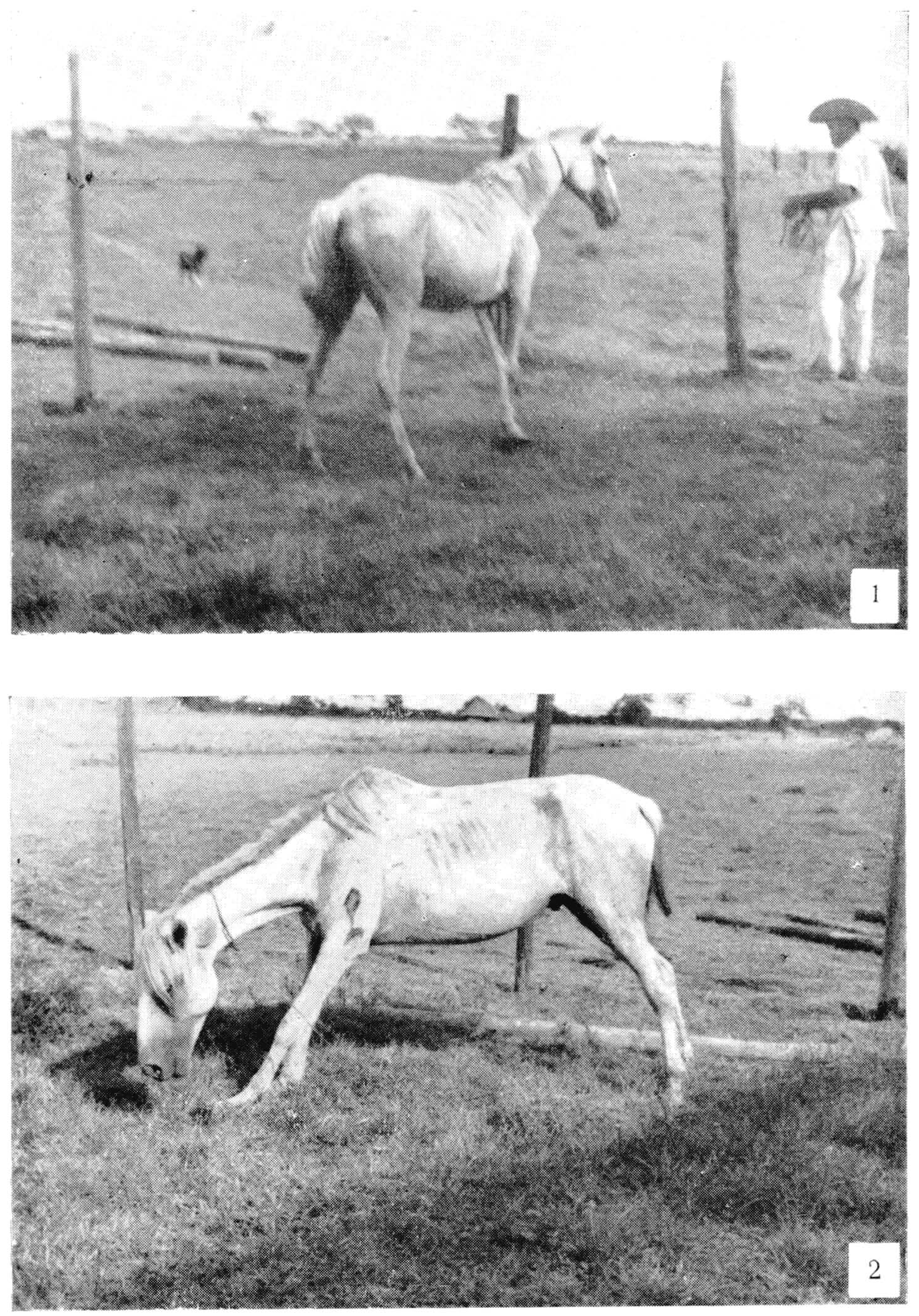

Jansen: Mal de cadeiras em Marajó 


\section{ESTAMPA 5}

Fig. 1 - Marajó - "Baixa rasa" no inverno.

Fig. 2 - Marajó - "Baixa rasa" no verão, vendo-se ao fundo "ilha de mato". 

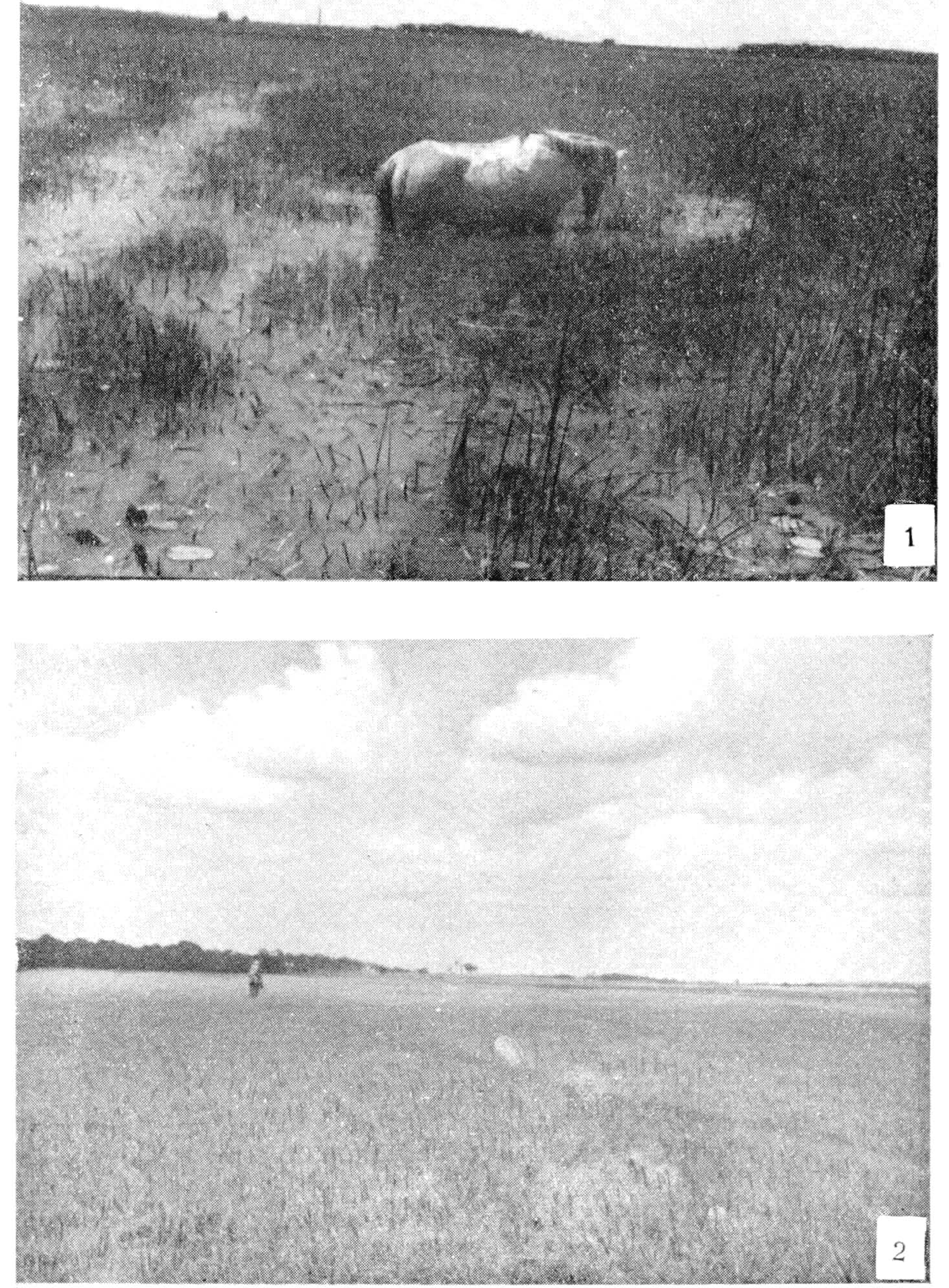

Jansen: Mal de cadeiras em Marajó 